ORIGINAL RESEARCH

\title{
Presence of L-Canavanine in Hedysarum alpinum Seeds and Its Potential Role in the Death of Chris McCandless
}

\author{
Jon Krakauer, BA; Ying Long, PhD; Andrew Kolbert, PhD; Shri Thanedar, PhD; Jonathan Southard, PhD \\ From the Knopf Doubleday Publishing Group, New York, NY (Mr Krakauer); the Avomeen Analytical Services, Ann Arbor, MI (Drs Long, \\ Kolbert, and Thanedar); and the Department of Chemistry, Indiana University of Pennsylvania, Indiana, PA (Dr Southard).
}

\begin{abstract}
Objective.-For the past 2 decades there has been vigorous disagreement over the purported toxicity of Hedysarum alpinum seeds, and whether the consumption of such seeds was a factor in the 1992 death of Chris McCandless, the subject of the book Into the Wild. Our objective was to confirm or disprove the presence of L-canavanine (a nonprotein amino acid known to induce systemic lupuslike symptoms in humans) in $H$ alpinum seeds.

Methods.-Liquid chromatography-tandem mass spectrometry analysis of $H$ alpinum seeds was performed.

Results.-Our analysis confirmed the presence of L-canavanine in $H$ alpinum seeds and demonstrated that it is a significant component of the seeds, with a concentration of $1.2 \%$ (weight/ weight), roughly half of that found in Canavalia ensiformis.

Conclusions.- The data led us to conclude it is highly likely that the consumption of $H$ alpinum seeds contributed to the death of Chris McCandless.

Key words: Hedysarum alpinum, Hedysarum mackenzii, L-canavanine, ODAP, McCandless, Into the Wild
\end{abstract}

\section{Introduction}

Twenty-four-year-old Christopher McCandless died in the Alaska wilderness on August 19, 1992, after subsisting for 114 days by hunting game and foraging for edible plants. Before going to Alaska he weighed 140 pounds. An autopsy performed approximately 3 weeks after his death determined that his remains weighed 67 pounds and lacked discernible subcutaneous fat. Starvation was cited as the probable cause of death. A diary, additional documents written on birch bark, and photographs recovered with McCandless' body indicated that starting on June 24, 1992, the roots of Hedysarum alpinum (L [Eskimo potato, wild potato, Alaska carrot]) became a staple of his meager diet. His diary was written on blank pages in the back of Tanaina Plantlore: Dena'ina K'et'una, ${ }^{1}$ an ethnobotany of the indigenous Dena'ina people of Southcentral Alaska, which McCandless relied on to identify edible plants.

The Dena'ina harvest $H$ alpinum roots when the ground thaws in the spring, and again in the autumn after the first

Corresponding author: Jon Krakauer, Penguin Random House, Doubleday Books, 1745 Broadway, New York, NY 10019 (e-mail: arrigetch@gmail.com). frosts, because the roots are juicy and tender during those periods. However, the Dena'ina do not dig $H$ alpinum roots during the high summer months because they become dry and tough. ${ }^{1}$ McCandless' diary indicates that he stopped eating $H$ alpinum roots on July 7, presumably because the advance of summer rendered them unpalatable. On July 14, he began harvesting and eating the seeds of $H$ alpinum to replace this major component of his diet (Figure 1). But on July 30, McCandless wrote in his diary, ominously, "EXTREMELY WEAK. FAULT OF POT[ATO] SEED. MUCH TROUBLE JUST TO STAND UP. STARVING. GREAT JEOPARDY." He died 20 days later. $^{2}$

All parts of $H$ alpinum have been thought to be nontoxic, ${ }^{3}$ and the roots of $H$ alpinum are specifically described as edible by Kari in Tanaina Plantlore. ${ }^{1}$ The $H$ alpinum roots are also described as edible in a popular guide to Alaskan wildflowers. ${ }^{4}$ Significantly, however, we could find no reports of the Dena'ina or any other Alaskan Natives using $H$ alpinum seeds as food, even during times of acute food shortage. Based on this conspicuous absence in the detailed ethnobotanical history of indigenous Alaskans, and based even more on the alarming references to $H$ alpinum seeds in 


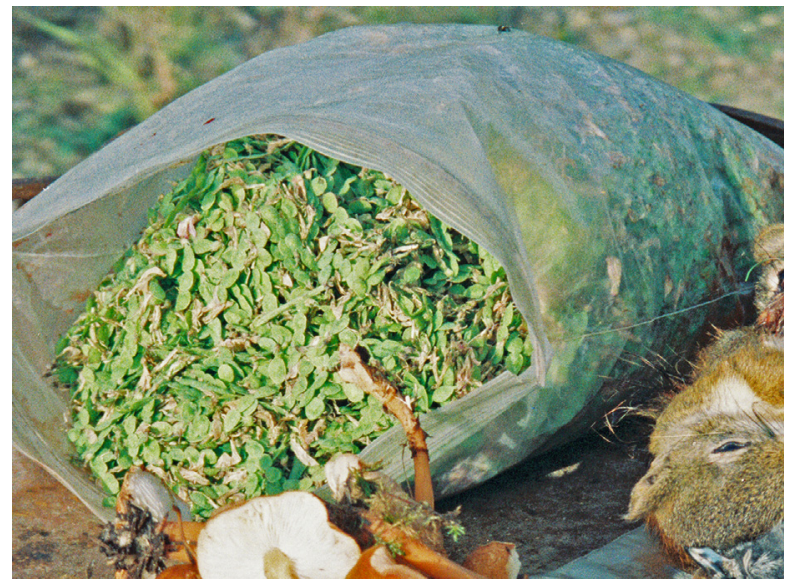

Figure 1. Hedysarum alpinum seeds harvested by Chris McCandless for food on July 18, 1992, in a 1-gallon Ziploc bag. Estimated dry weight $600 \mathrm{~g}$.

McCandless' diary, Krakauer speculated in Into the Wild ${ }^{2}$ (his widely read 1996 book about McCandless) that $H$ alpinum seeds contain swainsonine, a toxic alkaloid. According to Krakauer's hypothesis, the swainsonine in the seeds incapacitated McCandless to such a degree that it became impossible for him to hike out of the bush or hunt effectively, resulting in his death by starvation.

Krakauer's hypothesis was disputed with thin-layer chromatography (TLC) analyses and a cytotoxicity assay undertaken by Treadwell and Clausen, ${ }^{3}$ who found "no chemical basis for toxicity" in the seeds of $H$ alpinum or in a closely related species, Hedysarum mackenzii (Richardson [wild sweet pea, bear root]). The findings of Treadwell and Clausen were subsequently disputed in a hypothesis advanced by Ronald Hamilton, ${ }^{5}$ positing that $H$ alpinum seeds and $H$ mackenzii seeds were indeed toxic, and the toxic agent was not an alkaloid, but rather the nonprotein amino acid beta-N-oxalyl-L-alpha-beta diaminoproprionic acid, commonly referred to as L- $\beta$-ODAP or simply ODAP, which is a constituent of seeds in certain species of Fabaceae. Hamilton further conjectured that L- $\beta$-ODAPa neurotoxin identified in 1964 that causes lathyrism, a degenerative disease of the nervous system-played a central role in the death of McCandless. ${ }^{5,6}$

In 2004, TLC analyses of $H$ alpinum seeds and $H$ mackenzii seeds revealed prominent ninhydrin-positive spots with mobility essentially identical to that of L- $\beta$ ODAP (J. Southard and W. Gruber, unpublished data, 2004). However, the relatively low resolving power of the separation method precluded the positive identification of the seed component as L- $\beta$-ODAP. In 2013, seeking more definitive results, we conducted analyses employing reverse-phase high-pressure liquid chromatography and liquid chromatography-mass spectrometry
(LC-MS). These analyses detected a prominent $H$ alpinum seed component with the expected molar mass (MW 176) for L- $\beta$-ODAP. However, subsequent liquid chromatography-tandem mass spectrometry (LC-MS/ MS) analysis showed that the fragmentation-ion pattern for this component did not match that of L- $\beta$-ODAP.

These analyses nevertheless suggested the possibility that a significant concentration of a compound structurally similar to L- $\beta$-ODAP (MW 176.13) might be present in the seeds. An exhaustive review of the literature about nonprotein amino acids known to be deleterious to human health revealed that, in 1960, Birdsong et $\mathrm{al}^{7}$ determined by paper chromatography-trisodium pentacyanoammonioferrate colorimetric analysis that the nonprotein amino acid L-canavanine (MW 176.17) is a constituent of $H$ alpinum seeds. ${ }^{8}$ L-canavanine is a toxic antimetabolite stored in the seeds of many leguminous species to ward off predators. ${ }^{9}$

Figure 2 shows the structures of swainsonine, L- $\beta$ ODAP, and L-canavanine, all implicated as possible toxic compounds in $H$ alpinum. Of these, L-canavanine is the only one with published evidence showing it to be present in $H$ alpinum seeds. Given the controversy surrounding the toxicity of these seeds, we believed it would be valuable to reevaluate the presence of this known toxin. Methods for analysis of plant constituents have advanced significantly since the time of the original<smiles>O[C@H]1CCCN2C[C@H](O)[C@H](O)[C@H]12</smiles>

$$
\begin{gathered}
\text { Swainsonine } \\
\mathrm{C}_{8} \mathrm{H}_{15} \mathrm{NO}_{3} \\
173.21 \mathrm{~g} / \mathrm{mol}
\end{gathered}
$$<smiles>N[C@@H](CNC(=O)C(=O)O)C(=O)O</smiles>

L- $\beta$-ODAP $\mathrm{C}_{5} \mathrm{H}_{8} \mathrm{~N}_{2} \mathrm{O}_{5}$ $176.13 \mathrm{~g} / \mathrm{mol}$<smiles>NC(N)=NOCC[C@H](N)C(=O)O</smiles><smiles>N=C(N)NCCC[C@H](N)C(=O)O</smiles>

Figure 2. Compounds presumed or known to be present in Hedysarum alpinum. The alkaloid swainsonine and the amino acid beta- $\mathrm{N}$ oxalyl-L-alpha-beta diaminoproprionic acid (L-B-ODAP) have been suggested as possible toxic constituents but their presence has not been demonstrated. L-Canavanine, shown to be present in seeds, is an antimetabolite that can replace L-arginine during protein synthesis. 
investigation in 1960, and can now separate and quantitate even very similar compounds such as L- $\beta$-ODAP, Lcanavanine, and L-arginine that may not be well separated by paper or thin-layer chromatography methods. Additionally, subsequent to the report by Birdsong et $\mathrm{al}^{7}{ }^{7}$ it has been shown that the colorimetric detection reagent they used gives a similar color with the natural amino acid histidine, ${ }^{10}$ raising the possibility that a compound other than L-canavanine may have been detected. Therefore, it would be desirable to perform an analysis with both greater separating power and a more definitive detection method. Our goal in this work was to confirm or disprove the presence of L-canavanine in $H$ alpinum seeds by LC-MS/MS analysis, a highly specific and quantitative method not available at the time of the investigation by Birdsong et al.

\section{Methods}

The $H$ alpinum (L) seeds were collected on August 24, 2013, at Marsh Lake, Yukon Territory, Canada. Voucher specimens (COLO 544856) were deposited at the University of Colorado Museum Herbarium. The Lcanavanine reference standard ( $\geq 98 \%$ TLC, powder, from Canavalia ensiformis) was purchased from SigmaAldrich.

Using methodology adapted from Koh et al, ${ }^{11} 1.0 \mathrm{mg}$ L-canavanine was dissolved in $10 \mathrm{~mL}$ water and diluted $10 \times$ with $40 / 60$ water/acetonitrile; $516.2 \mathrm{mg}$ ground $H$ alpinum seeds were extracted with $10 \mathrm{~mL}$ water by ultrasonication for 2 hours. The extract was centrifuged at $5000 \mathrm{rpm}$ for 15 minutes. The supernatant was filtered with a $0.45-\mu \mathrm{m} \mathrm{RC}$ syringe filter and then diluted $10 \times$ with 40/60 water/acetonitrile before analysis. An Lcanavanine/seed extract mixture was prepared by mixing the $0.1 \mathrm{mg} / \mathrm{mL}$ L-canavanine with an equal volume of the prepared $5.16 \mathrm{mg} / \mathrm{mL}$ water-extract of $H$ alpinum seeds based on the peak intensities.

The L-canavanine standard and water extract of $H$ alpinum seeds were analyzed by LC-MS/MS according to the following method: apparatus, Thermo Finnigan Deca XP plus LC-MS with Surveyor PDA plus detector; column, Kenetex $2.6 \mu$ HILIC $50 \times 2.1 \mathrm{~mm}$; detector, ion trap mass spectrometer; source, Electrospray ionization positive; injection volume $5 \mu \mathrm{L}$; column temperature $30^{\circ} \mathrm{C}$; flow rate $0.3 \mathrm{~mL} / \mathrm{min}$; mobile phase A, $10 \mathrm{mM}$ ammonium formate $\mathrm{pH} 3.0$; mobile phase $\mathrm{B}$, acetonitrile $+0.1 \%$ formic acid; isocratic elution, $90 \% \mathrm{~A} /$ $10 \% \mathrm{~B}$.

\section{Results}

The LC-MS/MS analysis displayed a peak in L-canavanine (retention time [RT] 2.38 minutes) (Figure 3A) with MW
$176\left([\mathrm{M}+\mathrm{H}]^{+}=177\right)$ (Figure 4A); and 3 peaks in the water extract of $H$ alpinum seeds (RT 0.93, 1.38, and 2.40 minutes) (Figure 3C) with MW $176\left([\mathrm{M}+\mathrm{H}]^{+}=\right.$ 177) (Figure 4C). The MS/MS analysis showed the fragmentation ions from the peak with MW 176 $\left([\mathrm{M}+\mathrm{H}]^{+}=177\right)$ in L-canavanine (Figure 4B) matched the fragmentation ions from the peak with MW $176\left([\mathrm{M}+\mathrm{H}]^{+}=177\right)$ at RT 2.40 minutes in the water extract of $H$ alpinum seeds (Figure 4D). The coincidence of retention time, molecular ion, and fragmentation pattern is strong evidence for the presence of L-canavanine in the water extract of $H$ alpinum seeds.

To further confirm the presence of L-canavanine in the extract, a 50/50 mixture of L-canavanine and water extract of $H$ alpinum seeds was prepared and analyzed by LC-MS/MS. These data showed the coincident growth of the peak at retention time 2.42 minutes (Figure 3E) with the same MW $176\left([\mathrm{M}+\mathrm{H}]^{+}=177\right)$ (Figure 4E) and MS/MS fragmentation spectrum (Figure 4F), which confirms that the source of the peak is highly likely to be L-canavanine. The L-canavanine was quantified as $1.2 \%(\mathrm{w} / \mathrm{w})$ in $H$ alpinum seeds based on the integration of the peak area relative to the L-canavanine standard.

\section{Discussion}

Rosenthal $^{8,12}$ observed that L-canavanine, a natural homologue of L-arginine, can be assimilated into essentially any protein, supplanting L-arginine and creating aberrant canavanyl proteins that lack the capacity to form crucial ionic interactions, and thereby have the potential to disrupt myriad, fundamentally important biochemical reactions in a wide variety of organisms. "In this way," Rosenthal wrote, "L-canavanine becomes a highly toxic secondary plant constituent." The persistent presence of L-canavanine may result in apoptotic cell death. ${ }^{13}$ Paradoxically, L-canavanine thus has the potential to be both deleterious to human health and to function as a chemotherapeutic agent of clinical value in the treatment of human carcinomas. ${ }^{14}$

The toxicity of L-canavanine in animals has been well documented. Affleck ${ }^{15}$ observed cases of poisoning among cattle allowed to forage on jack beans, Canavalia ensiformis, the seeds of which contain approximately $2.5 \%$ L-canavanine by dry weight; symptoms included stiffness of the hindquarters, progressive weakness, emphysema, and hemorrhages of the lymph glands. Tschiersch ${ }^{16}$ conducted a series of feeding trials that showed L-canavanine sulfate induced toxic effects in mice. Obvious damage was observed after mice consumed L-canavanine at a concentration of $0.2 \mathrm{~g} / \mathrm{kg}$ 
L-canavanine reference standard

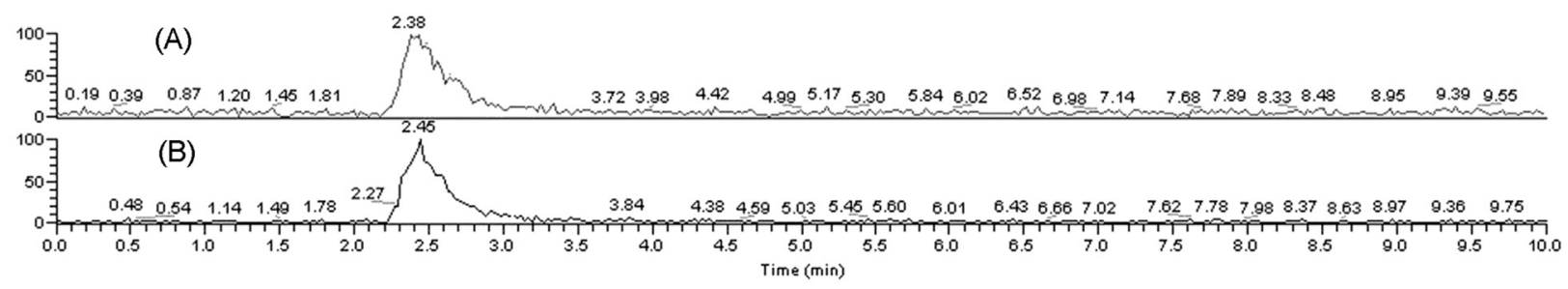

Water extract of $H$. alpinum seeds

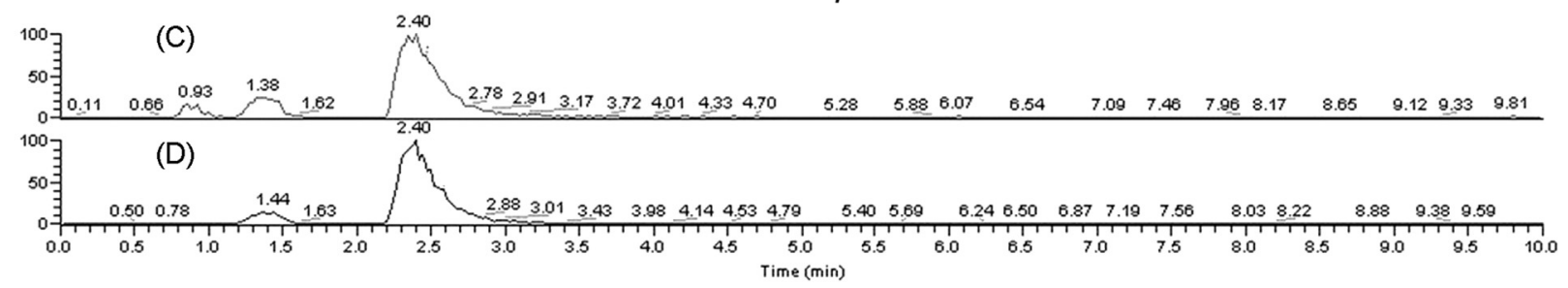

$50 / 50$ mixture of L-canavanine and water extract of $H$. alpinum seeds

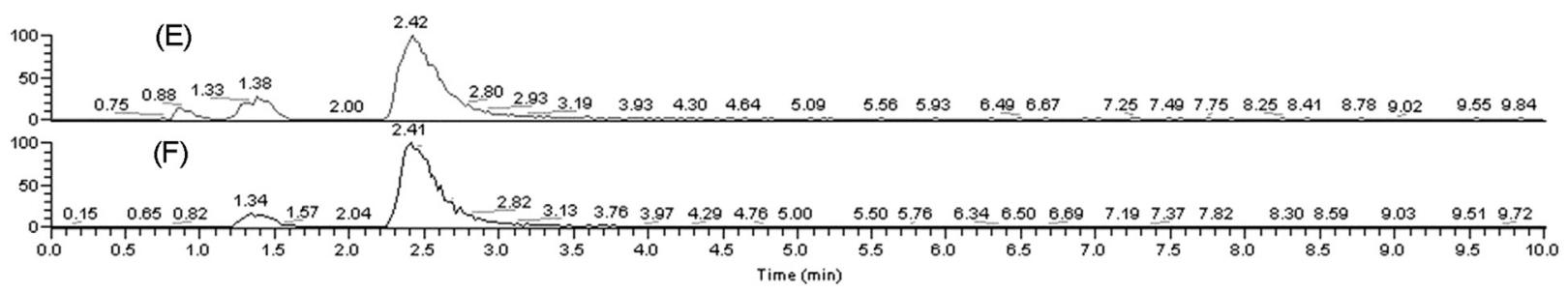

Figure 3. Liquid chromatography-tandem mass spectrometry (LC-MS/MS) analyses. (A) Extract ion chromatogram of L-canavanine reference standard $[\mathrm{M}+\mathrm{H}]^{+}$177. (B) Total ion chromatogram of L-canavanine reference standard $[\mathrm{M}+\mathrm{H}]^{+}$177. (C) Extract ion chromatogram of $[\mathrm{M}+\mathrm{H}]^{+}$ 177 from water extract of Hedysarum alpinum seeds. (D) Total ion chromatogram of MS/MS of $[\mathrm{M}+\mathrm{H}]^{+} 177$ from water extract of $\mathrm{H}$ alpinum seeds. (E) Extract ion chromatogram of $[\mathrm{M}+\mathrm{H}]^{+} 177$ from 50/50 mixture of L-canavanine and water extract of $H$ alpinum seeds. (F) Total ion chromatogram of MS/MS of $[\mathrm{M}+\mathrm{H}]^{+} 177$ from 50/50 mixture of L-canavanine and water extract of $H$ alpinum seeds.

mouse. All mice fed L-canavanine at a concentration of $2.0 \mathrm{~g} / \mathrm{kg}$ mouse died within 24 hours. Thomas and Rosenthal ${ }^{17}$ determined the median lethal dose for L-canavanine in adult rats to be $5.9 \pm 1.8 \mathrm{~g} / \mathrm{kg}$ after a single subcutaneous injection. At $4.0 \mathrm{~g} / \mathrm{kg}$, the rats became lethargic and their muscles twitched. Malinow et $\mathrm{al}^{18}$ reported that hematologic and serologic abnormalities similar to those observed in human systemic lupus erythematosus (SLE) developed in monkeys fed a diet of $40 \%$ alfalfa sprouts containing approximately $2 \%$ L-canavanine (w/w) for 7 months. The SLE-like syndrome disappeared after alfalfa sprouts were removed from the monkeys' diet, but the syndrome was reactivated when the animals were fed $1 \%(\mathrm{w} / \mathrm{w})$ L-canavanine sulfate.

There have been few clinical or epidemiological studies on L-canavanine-induced illness in humans. ${ }^{13}$ Tschiersch ${ }^{16}$ noted anecdotal reports of toxic effects in humans who ingested jack bean seeds, observing that "the scattered reports about poisoning by this plant probably stand in no relation to actual number of incidences that are caused by it in agricultural practice, because the cause is so difficult to recognize." Roberts and Hayashi ${ }^{19}$ reported a recurrence of SLE symptoms in 2 female patients who had been in remission after the patients ingested alfalfa tablets; high-pressure liquid chromatography analysis of the tablets in question demonstrated the presence of L-canavanine. Four cases of healthy patients who had SLE-like symptoms after consuming 12 to 24 alfalfa tablets per day for 3 weeks or more were reported by Alcocer-Varela and AlarconSegovia. ${ }^{20}$ Petri et $\mathrm{al}^{21}$ reported that a small epidemiological study in Baltimore suggested a significant association between eating alfalfa sprouts and developing lupus.

When McCandless walked into the wilderness on April 28, 1992, the only food in his backpack was a 10-pound bag of rice. After it was gone, he subsisted on 


\section{L-canavanine reference standard}

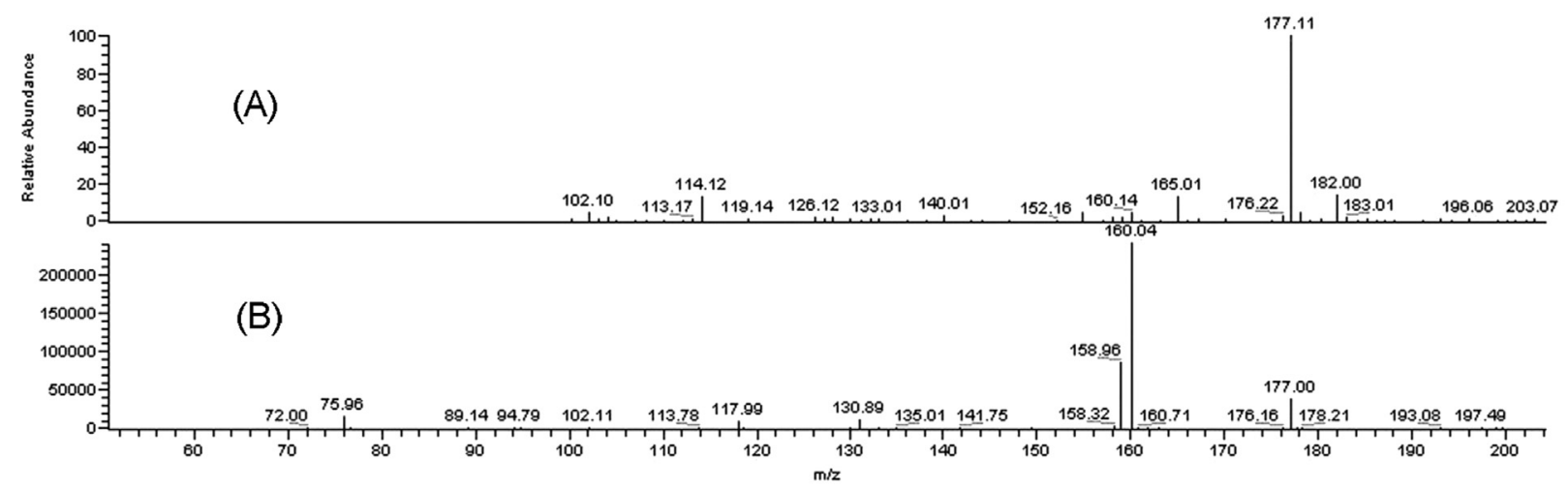

Water extract of $H$. alpinum seeds

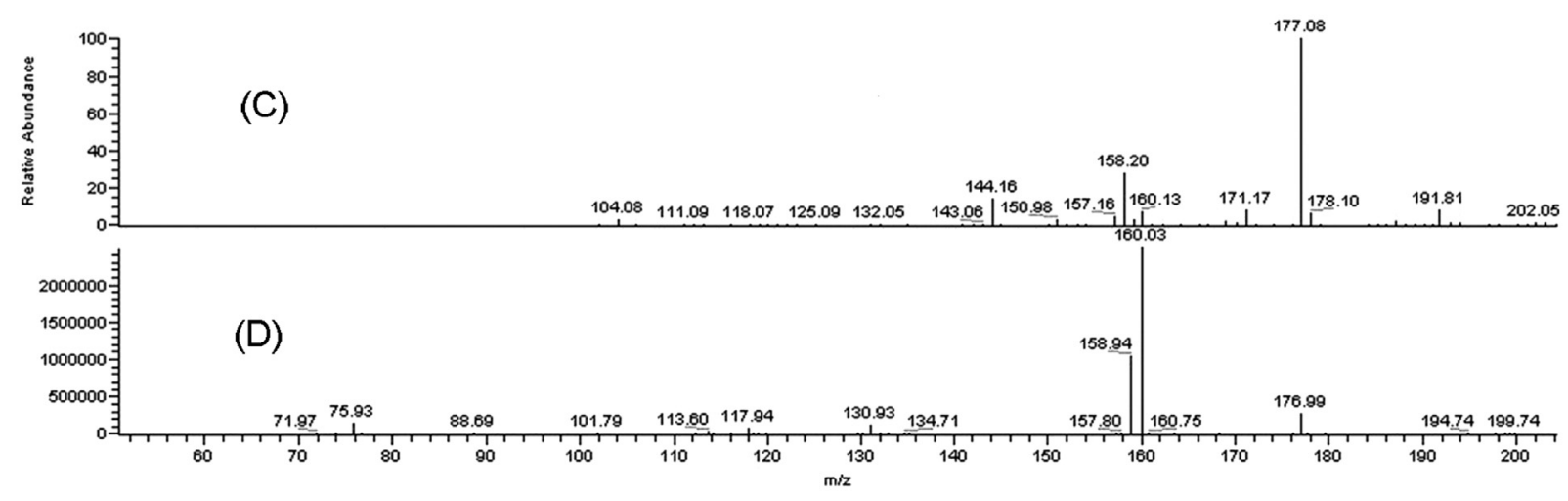

$50 / 50$ mixture of L-canavanine and water extract of $H$. alpinum seeds

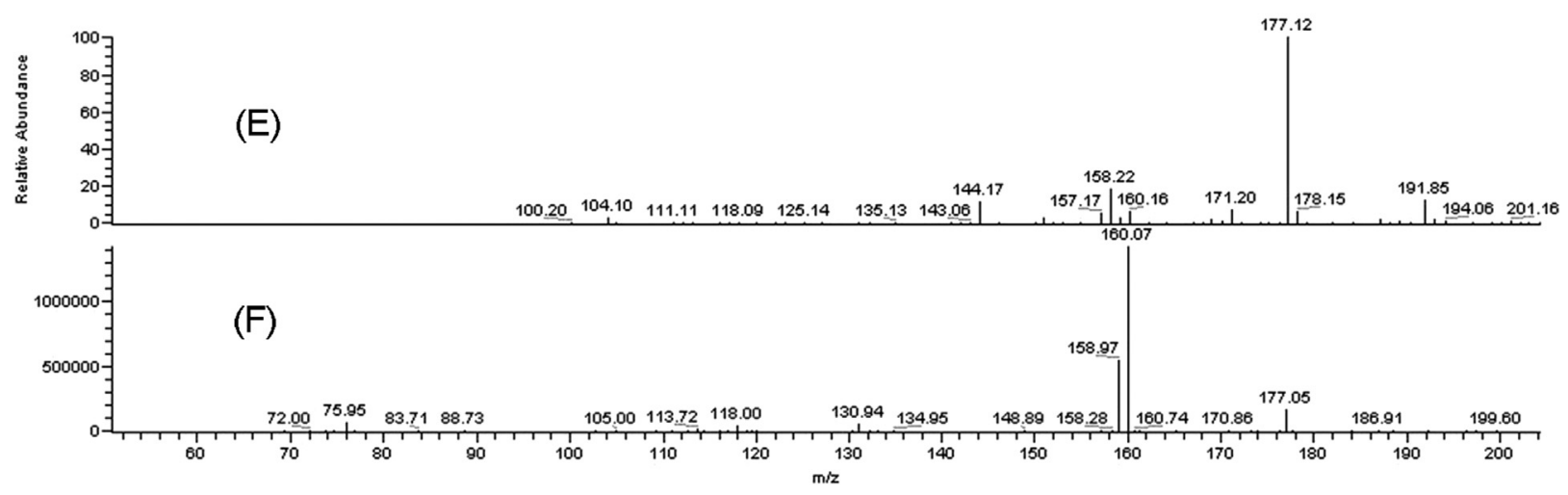

Figure 4. Liquid chromatography-tandem mass spectrometry (LC-MS/MS) analyses. (A) MS spectrum of L-canavanine reference standard $[\mathrm{M}+\mathrm{H}]^{+}$177. (B) MS/MS spectrum of L-canavanine reference standard $[\mathrm{M}+\mathrm{H}]^{+}$177. (C) MS spectrum of the peak of $[\mathrm{M}+\mathrm{H}]^{+} 177$ at retention time 2.40 minutes from water extract of Hedysarum alpinum seeds. (D) MS/MS spectrum of the peak of $[\mathrm{M}+\mathrm{H}]^{+} 177$ at retention time 2.40 minutes from water extract of $H$ alpinum seeds. (E) MS spectrum of the peak of $[\mathrm{M}+\mathrm{H}]^{+} 177$ at retention time 2.42 minutes from $50 / 50$ mixture of L-canavanine and water extract of $H$ alpinum seeds. (F) MS/MS spectrum of the peak of $[\mathrm{M}+\mathrm{H}]^{+} 177$ at retention time 2.42 minutes from $50 / 50$ mixture of L-canavanine and water extract of $H$ alpinum seeds.

a minimal diet that included squirrels, porcupines, small he was burning many more calories than he was birds, mushrooms, berries, lichens, wild rhubarb, $H$ consuming; his photos show that he had lost a significant alpinum roots, and part of a moose. During this period, amount of body weight by July 14, when he was driven 
by hunger to start harvesting and eating $H$ alpinum seeds, which were abundantly available in close proximity to his base camp (Figure 1). The paucity of McCandless' diet over the preceding months likely made him more susceptible to the toxic effects of Lcanavanine in the seeds. ${ }^{12}$ Although it is impossible to be certain that L-canavanine, per se, was the agent of his precipitous decline, McCandless was clearly convinced that something in the seeds incapacitated him: "EXTREMELY WEAK. FAULT OF POT[ATO] SEED. MUCH TROUBLE JUST TO STAND UP." L-canavanine is a plausible cause of the symptoms he described.

According to Akaogi et al, ${ }^{13}$ "It is likely that L-canavanine is incorporated into the host proteins more efficiently, and may show more significant effects, in conditions of arginine deficiency." The literature suggests that if a person made ill from L-canavanine stops ingesting it or starts ingesting adequate amounts of L-arginine, the adverse effects will eventually recede. ${ }^{13,18}$ It seems safe to assume that McCandless stopped eating $H$ alpinum seeds after his disquieting diary entry on July 30 , but the inadequacy of his diet precluded the possibility of recovery. The debilitation he experienced from the seeds appears to have been a tipping point. "DAY 100! MADE IT!" he wrote on August 5. "BUT IN WEAKEST CONDITION OF LIFE. DEATH LOOMS AS SERIOUS THREAT. TOO WEAK TO WALK OUT." On August 18 he penned his final diary entry, the number 113 with a circle drawn around it, a tally of the days he'd spent alone in the bush. ${ }^{2}$

The only experimental evidence directly addressing the question of toxicity of Hedysarum sp are the negative results of preliminary cytotoxic bioassays. Treadwell and Clausen $^{3}$ found that extracts of $H$ alpinum roots and seeds and $H$ mackenzii roots did not inhibit the growth of bacteria. Several factors complicate the interpretation of these results.

First, the samples tested were acetone extracts of plant material. As a very polar amino acid, L-canavanine is "freely soluble in water" but "practically insoluble" in ethanol. ${ }^{22}$ Acetone, with a polarity similar to that of ethanol, would therefore not effectively extract Lcanavanine. It (and other very polar plant constituents) would be absent, or present in very low amounts, in the bioassay samples.

Second, we could not find any information in the literature regarding the effect of L-canavanine on the bacteria used, Bacillus megaterium. There is, however, a report of the effect of L-canavanine, alone and in combination with L-arginine, on the growth of several species of bacteria. ${ }^{23}$ It was found that "For some, but not all, bacteria tested, canavanine was an effective growth inhibitor." Also, as expected for an antimetabolite mechanism, growth inhibition by Lcanavanine depends on the relative concentrations of the 2 amino acids. In the bioassay conducted by Treadwell and Clausen, ${ }^{3}$ L-canavanine concentrations are expected to be low (due to inefficient extraction), and L-arginine concentrations may be relatively high (the bacteria are inoculated in a rich medium). As shown by Volcani and Snell, ${ }^{23}$ these conditions tend to minimize or negate any effect of L-canavanine on bacterial growth rate.

Third, Treadwell and Clausen cite Lokvam and Braddock $^{24}$ for the bioassay method. Lokvam and Braddock $^{24}$ report the use of the bioassay in a meaningful context. They assess the antibiotic activity of plant extracts against bacterial species likely to be present on pollinators of the plant in question. ${ }^{24,25}$ In contrast, Treadwell and Clausen ${ }^{3}$ use the effects of Hedysarum extracts on a soil bacterium (B megaterium) to evaluate the toxicity of the plants to humans. There are many biochemical differences in the uptake and metabolism of amino acids among bacterial species, and between humans and bacteria. Extrapolating from no inhibition of growth of a single bacterial species to nontoxicity in humans without validation is questionable.

\section{STUDY LIMITATIONS}

Considering the dearth of existing experimental evidence, the degree of toxicity of $H$ alpinum seeds to humans remains uncertain. Although McCandless' diary and photographs indicate $H$ alpinum seeds were a major component of his diet from July 14 until July 30, there is no way of knowing the quantity of seeds he consumed during this period.

\section{Conclusion}

Our results confirmed the presence of L-canavanine (an antimetabolite with demonstrated toxicity in mammals) as a significant component of $H$ alpinum seeds and quantify its abundance with a concentration of $1.2 \%$ (weight/weight). This is roughly half of that found in Canavalia ensiformis (L), one of the best-studied natural sources of L-canavanine. In the case of Christopher McCandless, there is evidence that $H$ alpinum seeds constituted a significant portion of his meager diet during a period before his death. Based on this and what is known about the toxic effects of L-canavanine, we make the logical conclusion that, under these conditions, it is highly likely that the ingestion of relatively large amounts of this antimetabolite was a contributing factor to his death. 
The death of Chris McCandless should serve as a caveat to other foragers: even when some parts of a plant are known to be edible, other parts of the same species may contain dangerous concentrations of toxic compounds. Additionally, there may be seasonal, as well as ecotypic, variations in the concentrations of Lcanavanine between various communities of $H$ alpinum. Further studies are needed to determine the range of Lcanavanine concentrations among different populations of the plant. Given the known toxic properties of Lcanavanine and its established presence in $H$ alpinum seeds, it seems prudent to use caution before ingesting these seeds, especially as a significant part of the diet.

\section{References}

1. Kari PR. Tanaina Plantlore: Dena'ina K'et'una. Fairbanks, AK: Alaska Native Language Center; 1991.

2. Krakauer J. Into the Wild. New York, NY: Villard; 1996.

3. Treadwell EM, Clausen TP. Is Hedysarum mackenziei (wild sweet pea) actually toxic? Ethnobot Res Applic. 2008;6:319-321.

4. Pratt VE. Wildflowers Along the Alaska Highway. Anchorage, AK: Alaskakrafts; 1991.

5. Hamilton R. The silent fire: ODAP and the death of Chris McCandless. 2012. Available at: http://www.christo phermccandless.info/Ronald-Hamilton/ronald-hamilton-in tothewild1.html. Accessed May 7, 2014.

6. Krakauer J. How Chris McCandless died. 2013. Available at: http://www.newyorker.com/online/blogs/books/2013/09/ how-chris-mccandless-died.html. Accessed May 7, 2014.

7. Birdsong BA, Alston R, Turner BL. Distribution of canavanine in the family Leguminosae as related to phyletic groupings. Can J Botany. 1960;38:499-505.

8. Rosenthal GA. Biological effects and mode of action of Lcanavanine, a structural analogue of L-arginine. $Q$ Rev Biol. 1977:52:155-178.

9. Rosenthal GA. L-Canavanine: a higher plant insecticidal allelochemical. Amino Acids. 2001;21:319-330.

10. Rosenthal GA, Dahlman DA. A cautionary note on pentacyanoammonioferrate use for determining Lcanavanine occurrence in biological materials. Experientia. 1982;38:1034-1035.
11. Koh HL, Lau AJ, Chan EC. Hydrophilic interaction liquid chromatography with tandem mass spectrometry for the determination of underivatized dencichine (beta-N-oxalylL-alpha,beta-diaminopropionic acid) in Panax medicinal plant species. Rapid Commun Mass Sp. 2005;19:12371244.

12. Rosenthal GA. Biochemical basis for the deleterious effects of L-canavanine. Phytochemistry. 1991;30:10551058.

13. Akaogi J, Barker T, Kuroda Y, et al. Role of non-protein amino acid L-canavanine in autoimmunity. Autoimmun Rev. 2006;5:429-435.

14. Rosenthal GA. L-canavanine: a potential chemotherapeutic agent for human pancreatic cancer. Pharm Biol. 1998; 36:194-201.

15. Affleck H. Jack bean poisoning in cattle. Rhodesia Agric J. 1961;58:21.

16. Tschiersch B. [Zur toxischen wirkung der jackbohne. Pharmazie. 1962;17:621-623.

17. Thomas DA, Rosenthal GA. Toxicity and pharmacokinetics of the nonprotein amino acid L-canavanine in the rat. Toxicol Appl Pharm. 1987;91:395-405.

18. Malinow MR, Bardana EJ, Pirofsky B, Craig S. Systemic lupus erythematosus-like syndrome in monkeys fed alfalfa sprouts: role of a nonprotein amino acid. Science. $1982 ; 216: 415-417$.

19. Roberts JL, Hayashi JA. Exacerbation of SLE associated with alfalfa ingestion. $N$ Engl J Med. 1983;308:1361.

20. Alcocer-Varela J, Alarcon-Segovia D. Reply. Arthritis Rheum. 1985;28:1200.

21. Petri M, Thompson E, Abusuwwa R, Huang J. Garret E. BALES: the Baltimore lupus environmental study [abstract]. Arthritis Rheum. 2001;44(Suppl 9):331.

22. O'Neil MJ, ed. The Merck Index. Whitehouse Station, NJ: Merck; 2006.

23. Volcani BE, Snell EE. The effects of canavanine, arginine, and related compounds on the growth of bacteria. J Biol Chem. 1948;174:893-902.

24. Lokvam J, Braddock JF. Anti-bacterial function in the sexually dimorphic pollinator rewards of Clusia grandiflora (Clusiaceae). Oecologia. 1999;119:534-540.

25. Lokvam J, Braddock JF, Reichardt PB, Clausen TP. Two polyisoprenylated benzophenones from the trunk latex of Clusia grandiflora (Clusiaceae). Phytochemistry. 2000;55: 29-34. 